\title{
Failure of prophylaxis for bacterial endocarditis: American Heart Association Registry
}

Sir,

The American Heart Association (AHA) recognises that its current recommendations for antibiotic prophylaxis are necessarily empirical ${ }^{1}$ because important clinical information on the efficacy of antibiotic prophylaxis of bacterial endocarditis is lacking. The present recommendations are therefore based upon secondary sources of information such as the relative propensity of various procedures to cause bacteraemia, in vitro studies of bacteria recovered from the blood, the effect of antibiotics on bacteraemias, the susceptibility of various heart lesions to infection, anecdotal case reports, and study of experimental models.

Although over 30 individual cases of apparent failure of prophylaxis have been recorded, many of our colleagues have rightly pointed out that the evidence indicating that a significant number of failures actually occurs is inconclusive. This question is of considerable medical and medicolegal importance because of the frequent necessities for measures to prevent endocarditis, and because of the serious consequences of failure to prevent the disease.

In an attempt to accumulate useful epidemiological data, the AHA Committee has established a Registry to record cases of apparent failure of antibiotic prophylaxis of bacterial endocarditis. We are now soliciting case reports. Notification may be made on a simple preprinted postcard, which will require only identification of the patient and the name, address, and telephone number of the person referring the case. These postcards will be made available to doctors and dentists and to any other person or organisation requesting them from the AHA or from one of us. Alternatively, a case may be reported directly to one of us, at the address or telephone number listed below. After notification, one of us will follow up with a telephone call, in order to gather sufficient information to evaluate the case. All such information will be confidential.

Though there are obvious disadvantages to any retrospective evaluation such as this, the practical impossibility of conducting a prospective trial of different modes of prophylaxis has caused us to seek alternative means of gathering data. We hope that a useful body of information may be accumulated, which may influence future recommendations for prophylaxis of endocarditis.

Alan L Bisno,
Chief, Division of Infectious Diseases
University of Tennessee,
Center Health Sciences,
Room 241-Dobbs,
951 Court Avenue,
Memphis, Tennessee 38163
(901) 528-5786

David T Durack, Associate Professor and Chief, Division of Infectious Diseases, Duke University Medical Center, Durham, North Carolina 27710 (919) 684-2660

\section{David W Fraser,} Chief, Special Pathogens Branch, Bacterial Diseases Division, Bureau of Epidemiology, Center for Disease Control, Atlanta, Georgia 30333 (404) 329-3687

Edward L Kaplan, Department of Pediatrics, Box 94, University of Minnesota, Minneapolis, Minnesota 55455 (612) 373-8938

Mark A Oliveira,
Chief, Scientific Councils,
American Heart Association,
AHA National Center,
7320 Greenville Avenue,
Dallas, Texas 75231
(214) 750-5431

\section{Reference}

${ }^{1}$ American Heart Association Committee on Rheumatic Fever and Bacterial Endocarditis. Prevention of bacterial endocarditis. Circulation 1977; 56: 139A-43A. 